\title{
Substrate Specificity of Low-Molecular Mass Bacterial DD-Peptidases
}

\author{
Venkatesh V. Nemmara, ${ }^{\dagger}$ Liudmila Dzhekieva, ${ }^{\dagger}$ Kumar Subarno Sarkar, ${ }^{\dagger}$ S. A. Adediran, ${ }^{\dagger}$ Colette Duez, ${ }^{\ddagger}$ \\ Robert A. Nicholas, ${ }^{\S}$ and R. F. Pratt ${ }^{*, \dagger}$
}

†Department of Chemistry, Wesleyan University, Lawn Avenue, Middletown, Connecticut 06459, United States

${ }^{\ddagger}$ Centre d'Ingéniere des Proteines, Université de Liège, B-4000 Sart Tilman, Liège, Belgium

${ }^{\S}$ Department of Pharmacology, University of North Carolina, Chapel Hill, North Carolina 27599-7365, United States

\section{Supporting Information}

ABSTRACT: The bacterial DD-peptidases or penicillin-binding proteins (PBPs) catalyze the formation and regulation of cross-links in peptidoglycan biosynthesis. They are classified into two groups, the high-molecular mass (HMM) and lowmolecular mass (LMM) enzymes. The latter group, which is subdivided into classes A-C (LMMA, -B, and -C, respectively), is believed to catalyze DD-carboxypeptidase and endopeptidase reactions in vivo. To date, the specificity of their reactions with particular elements of peptidoglycan structure has not, in general, been defined. This paper describes the steady-state kinetics of hydrolysis of a series of specific

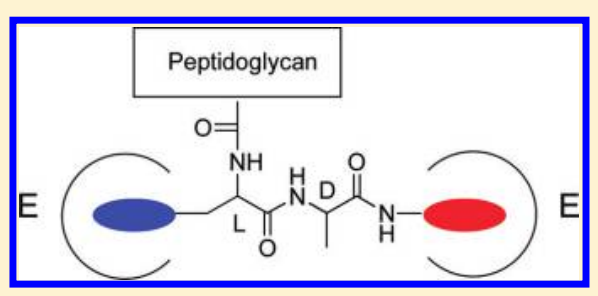
peptidoglycan-mimetic peptides, representing various elements of stem peptide structure, catalyzed by a range of LMM PBPs (the LMMA enzymes, Escherichia coli PBP5, Neisseria gonorrhoeae PBP4, and Streptococcus pneumoniae PBP3, and the LMMC enzymes, the Actinomadura R39 DD-peptidase, Bacillus subtilis PBP4a, and N. gonorrhoeae PBP3). The R39 enzyme (LMMC), like the previously studied Streptomyces R61 DD-peptidase (LMMB), specifically and rapidly hydrolyzes stem peptide fragments with a free N-terminus. In accord with this result, the crystal structures of the R61 and R39 enzymes display a binding site specific to the stem peptide $\mathrm{N}$-terminus. These are water-soluble enzymes, however, with no known specific function in vivo. On the other hand, soluble versions of the remaining enzymes of those noted above, all of which are likely to be membrane-bound and/or associated in vivo and have been assigned particular roles in cell wall biosynthesis and maintenance, show little or no specificity for peptides containing elements of peptidoglycan structure. Peptidoglycan-mimetic boronate transition-state analogues do inhibit these enzymes but display notable specificity only for the LMMC enzymes, where, unlike peptide substrates, they may be able to effectively induce a specific active site structure. The manner in which LMMA (and HMM) DD-peptidases achieve substrate specificity, both in vitro and in vivo, remains unknown.

$\mathrm{T}$ he bacterial DD-peptidases catalyze the final steps of peptidoglycan (cell wall) biosynthesis ${ }^{1,2}$ and are efficiently inhibited by $\beta$-lactam antibiotics. ${ }^{3}$ Resistance to these antibiotics continues to emerge, particularly from evolution of new $\beta$-lactamases, enzymes that catalyze hydrolytic destruction of $\beta$-lactams, but also by the evolution and dispersal of $\beta$-lactam-resistant DD-peptidases. ${ }^{4,5}$ Important examples of pathogenic bacteria in which $\beta$-lactam-resistant DD-peptidases play a significant role in resistance are Staphylococcus aureus (MRSA), ${ }^{6}$ Streptococcus pneumoniae, ${ }^{7,8}$ Enterococcus faecium, ${ }^{9}$ and Neisseria gonorrhoeae. ${ }^{10}$

Many attempts have been made to develop new $\beta$-lactams effective against mutant DD-peptidases, ${ }^{11,12}$ but, to date, these have not been completely successful. The ideal of a broadspectrum $\beta$-lactam not susceptible to loss of effectiveness through DD-peptidase mutation has been difficult to achieve. To a considerable extent, this is likely due to the largely trial and error approach to new $\beta$-lactams. The alternative approach of targeting the reaction center and the common and essential structural features of the DD-peptidase active site has not been pursued as vigorously. Classically, one would expect substrate analogue inhibitors, mechanism-based and transition-state analogues, to be effective. Few such examples are known, although the reasons for this are not clear. The first issue to be taken into account in the design of such inhibitors is the structure of the substrate itself and the affinity of the enzyme for this substrate. Curiously, there is much less information about these essentials for DD-peptidases than one would imagine. For most enzymes, especially those studied for more than 40 years, the identity of the natural substrate at least is known!

The bacterial DD-peptidases have been classified largely on the basis of structural similarities, although these are probably directly related to function. ${ }^{13}$ They can first be divided into two groups, high-molecular mass (HMM) and low-molecular mass (LMM) enzymes, where the dividing line is approximately $50 \mathrm{kDa}$. Each of these groups can be subdivided, the HMM group into HMMA and HMMB classes and the LMM group into LMMA, -B and -C classes. The HMMA DD-peptidases are bifunctional enzymes that catalyze both the transglycosylation and transpeptidation reactions of incorporation of stem peptide monomers into peptidoglycan, whereas members of the HMMB group are thought to catalyze only the transpeptidation

Received: August 22, 2011

Revised: October 12, 2011

Published: October 27, 2011 
reaction. Both of these classes are essential to bacterial survival and are therefore the primary targets of $\beta$-lactam antibiotics. The LMM groups are also inhibited by $\beta$-lactams, but because they are not essential to bacterial survival, at least in the short term, they are not considered viable antibiotic targets. The LMM enzymes are thought to be DD-carboxypeptidases and/or endopeptidases, which regulate the extent of peptide crosslinking in peptidoglycan. ${ }^{14,15}$

Structure 1 shows the stem peptide, the monomer unit of peptidoglycan polymerization, of a typical bacterium. These monomers, as lipid adducts (lipid II), are incorporated into nascent peptidoglycan in the transglycosylation and transpeptidation reactions mentioned above. ${ }^{1,2}$ Alternatively, the terminal D-alanine may be hydrolytically cleaved in a DD-carboxypeptidase reaction. The sites of these reactions are also shown in 1. Transpeptidation and carboxypeptidation reactions also may occur in previously cross-linked peptidoglycan. Structure $\mathbf{2}$ is a dimer in which two polysaccharide strands are cross-linked and the sites of the transpeptidase and carboxypeptidase reactions are indicated. Finally, dimers and more highly cross-linked peptidoglycan are also subject to endopeptidase hydrolysis, as shown in 2 . Together, the carboxypeptidase and endopeptidase reactions regulate the degree of cross-linking of the peptidoglycan. All of these reactions are thought to proceed through a covalent acylenzyme intermediate derived from reaction of a nucleophilic serine residue at the DD-peptidase active site (Scheme 1).

\section{Scheme 1}

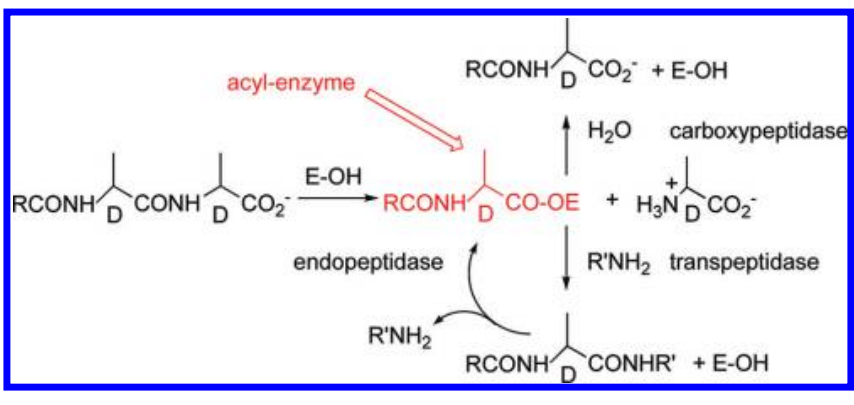

One would expect, therefore, that the substrate(s) of $\mathrm{DD}$ peptidases would include elements of $\mathbf{1}$ and $\mathbf{2}$ and that these enzymes would show specificity toward peptides containing these elements. To a large extent, however, such specificity has not yet been systematically investigated, even in vitro. The situation in vivo is even more uncertain for most of these enzymes.

A clear exception to this statement is provided by one particular DD-peptidase, the LMMB enzyme from Streptomyces R61. This enzyme was studied for many years by the Liège group of Ghuysen and Frère. ${ }^{3,16}$ They showed that the R61 DDpeptidase catalyzed the hydrolysis of certain small peptides such as $N, N^{\prime}$-diacetyl-L-lysyl-D-alanyl-D-alanine, $3,{ }^{16}$ and similar (thio)depsipeptides. ${ }^{17}$ More recently, it has been shown that peptide 4 is a very specific substrate for this enzyme $\left(k_{\mathrm{cat}} / K_{\mathrm{m}}=\right.$ $\left.8.7 \times 10^{6} \mathrm{~s}^{-1} \mathrm{M}^{-118}\right)$, much more reactive than generic peptide $3\left(k_{\mathrm{cat}} / K_{\mathrm{m}}=3.5 \times 10^{3} \mathrm{~s}^{-1} \mathrm{M}^{-1}\right)$. The specificity of 4 as a substrate is certainly understandable in view of the Streptomyces R61 stem peptide structure that includes the $N$-glycyl-L- $\alpha$ aminopimelyl moiety as the $\mathrm{N}$-terminus.

$\mathrm{X}$-ray crystal structures of complexes of $\mathbf{4}$ with the enzyme show what seems to be a very tight and specific binding site for the $N$-glycyl-L- $\alpha$-aminopimelyl side chain of $4 .^{19}$ The R61

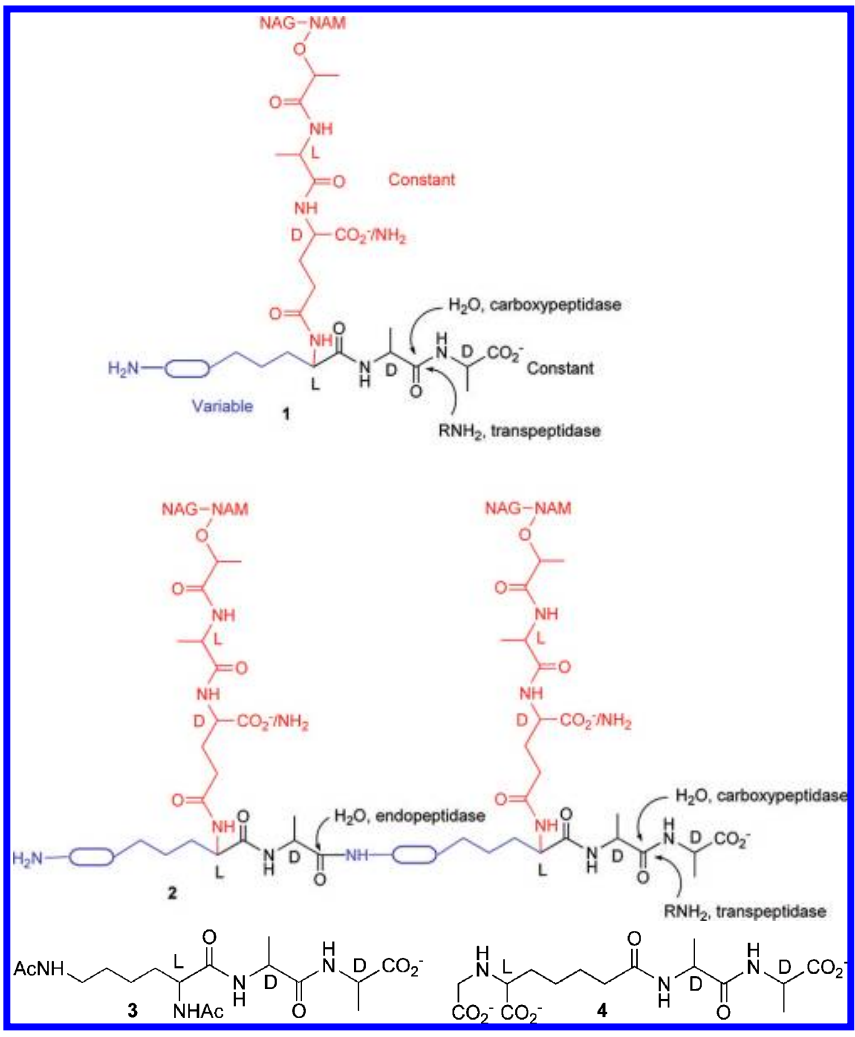

DD-peptidase appears to have only weak endopeptidase activity in vitro, ${ }^{20-22}$ and although it does catalyze transpeptidation reactions between $\mathbf{4}$ and small acceptors, extended acceptors, such as one would expect in a natural substrate, are ineffective. ${ }^{20,21}$ In summary, these data support the proposition that the R61 DD-peptidase is a DD-carboxypeptidase, at least in vitro, whose preferred substrate is the stem peptide monomer, 1. Data of this detail pertaining to substrate specificity are not available for virtually any other DD-peptidase, although there is considerable information concerning the Actinomadura R39 DD-peptidase, ${ }^{23-25}$ including a recent systematic study from this laboratory. ${ }^{26}$ In this case, a peptidoglycan-mimetic boronate was also shown to be a very potent inhibitor, most likely a transition-state analogue. ${ }^{27}$

In this paper, we explore the specificity of several LMMA and LMMC DD-peptidases, employing a series of peptidoglycanmimetic peptide substrates and boronate inhibitors. The aim was to determine whether peptidoglycan mimetics are generally useful leads to DD-peptidase inhibitors and thus, perhaps, to new antibiotics. In particular, the issue of whether more extended peptides, related to dimer and oligomer peptidoglycan structures, might lead to stronger interactions with these enzymes was evaluated.

\section{MATERIALS AND METHODS}

The purified enzymes were prepared as described: the Actinomadura R39 DD-peptidase, ${ }^{28}$ Escherichia coli PBP5 (EcPBP5), ${ }^{29}$ N. gonorrhoeae PBP 3 (NgPBP3) $^{30}$ and PBP4 (NgPBP4), ${ }^{31}$ Bacillus subtilis PBP4a (BsPBP4a), ${ }^{32}$ and S. pneumoniae PBP3 (SpPBP3). ${ }^{33}$ The following peptides were purchased commercially and used as received: 10 (NeoMPS), 3 and 13 (Sigma-Aldrich), and 14-19 (New England Peptide). Peptides 7-9 were prepared by standard peptide methodology; the details are given in the Supporting Information. The syntheses of 5, 22, and 23 have been previously described, ${ }^{34,35}$ 


\section{Chart 1}

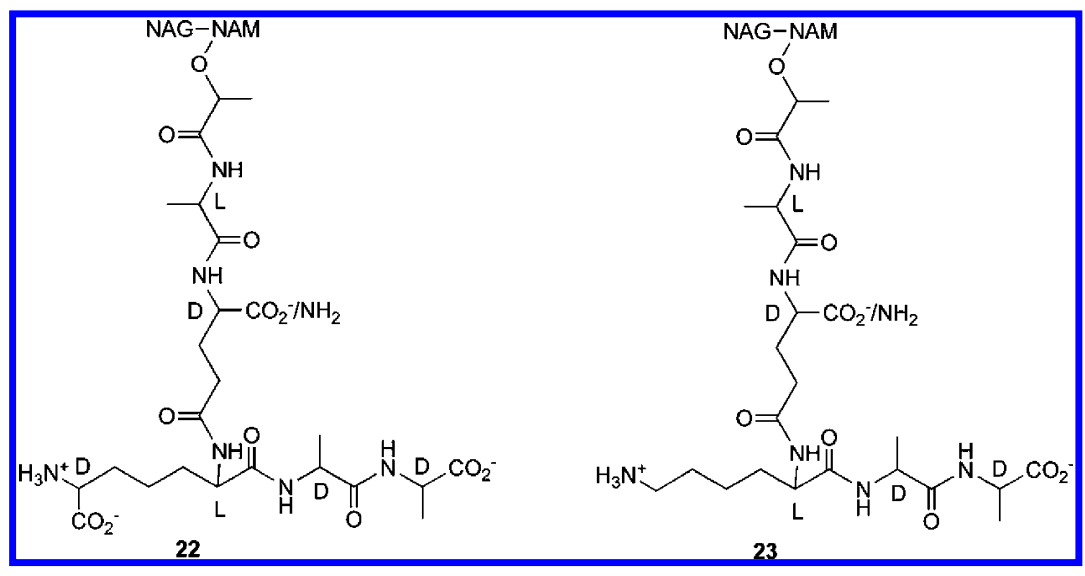

and that of 6 will be described elsewhere. Synthesis of boronate 11 has been described previously; ${ }^{27}$ those of 12, 20, and 21 were conducted similarly and are described in the Supporting Information.

A general ${ }^{1} \mathrm{H}$ NMR experiment was first used to determine the products of reactions of the R39 DD-peptidase and BsPBP4a toward peptides 7-9. ${ }^{1} \mathrm{H}$ NMR spectra of solutions of these peptides $(3-5 \mathrm{mM})$ in deuterated phosphate buffer $(20 \mathrm{mM})$ were recorded before and after the addition of enzyme $(0.1-0.3$ $\mu \mathrm{M})$. Further spectra were recorded at various time intervals until the reaction was complete. Similar experiments were performed with SpPBP3 and peptides 14-18. The lack of reaction of 16 and 17 with BsPBP3 was checked by highperformance liquid chromatography (HPLC) where the absence of $\alpha$-N-acetyllysine was confirmed.

Kinetic Methods. Steady-state kinetics experiments were conducted under conditions previously established to generate high, stable activity: R39 DD-peptidase and BsPBP4a, $20 \mathrm{mM}$ phosphate buffer ( $\mathrm{pH} 7.5)$ at $25{ }^{\circ} \mathrm{C}$; EcPBP5, NgPBP3, and NgPBP4, $0.1 \mathrm{M}$ sodium pyrophosphate and $10 \%$ glycerol ( $\mathrm{pH} 8.5$ ) at $37{ }^{\circ} \mathrm{C}$; SpPBP3, $20 \mathrm{mM}$ phosphate buffer ( $\mathrm{pH} 7.0$ ) at $37{ }^{\circ} \mathrm{C}$. Measurements of enzymatic activity with peptides were determined spectrophotometrically, where the loss of a peptide bond was monitored at wavelengths between 215 and $235 \mathrm{~nm}$. Initial rates were fitted to the Henri-MichaelisMenten equation by a nonlinear least-squares procedure to yield values of $k_{\text {cat }}$ and $K_{\mathrm{m}}$. The range of peptide substrate concentrations employed was $0-1$ or $2 \mathrm{mM}$, and enzyme concentrations were, typically, $0.1-0.4 \mu \mathrm{M}$. In cases where substrate concentrations approaching $K_{\mathrm{m}}$ were not achieved, values of $k_{\text {cat }} / K_{\mathrm{m}}$ were obtained by nonlinear least-squares exponential fits to the total progress curve. In the case of the Actinomadura R39 DD-peptidase enzyme, the $K_{\mathrm{m}}$ of peptide substrate 9 was determined separately as the $K_{\mathrm{i}}$ value from a competition experiment in which thiolactate $24^{21}$ was the substrate. Equilibrium constants for inhibition of the enzymes by $11,12,20$ and 21 were obtained from steady-state competition experiments in which $N$-phenylacetylglycyl-Dthiolactate $^{35}$ was employed as a chromophoric $(245 \mathrm{~nm}$, $\left.\Delta \varepsilon=2500 \mathrm{~cm}^{-1} \mathrm{M}^{-1}\right)$ substrate $(0.5 \mathrm{mM})$. The reaction conditions were as follows: R39, boronate $\mathbf{1 1}$ and $\mathbf{1 2}$ concentrations of $0.1-1.0 \mu \mathrm{M}$ and $0.1-1.0 \mathrm{mM}$, respectively, enzyme concentration of $94.5 \mathrm{nM}$, and substrate $K_{\mathrm{m}}$ of $38.4 \mu \mathrm{M}$ (S. A. Adediran and R. F. Pratt, unpublished observations); PBP4a, boronate 11 and 12 concentrations of $0.1-1.0 \mu \mathrm{M}$ and 0.1-1.0 mM, respectively, enzyme concentration of $167 \mathrm{nM}$, and substrate $K_{\mathrm{m}}$ of $>1 \mathrm{mM}$; NgPBP3, boronate 11 and 12 concentrations of $10-250 \mu \mathrm{M}$ and $0.1-1.0 \mathrm{mM}$, respectively, enzyme concentration of $10.4 \mathrm{nM}$, and substrate $K_{\mathrm{m}}$ of $>1 \mathrm{mM}$; NgPBP4, boronate 11 and 12 concentrations of $1.0-10 \mu \mathrm{M}$ and 0.1-1.0 mM, respectively, enzyme concentration of $150 \mathrm{nM}$, and substrate $K_{\mathrm{m}}$ of $1.6 \mathrm{mM}$; EcPBP5, boronate 11 and 12 concentrations of $0.1-1.0 \mathrm{mM}$, enzyme concentration of $137 \mathrm{nM}$, and substrate $K_{\mathrm{m}}$ of $220 \mu \mathrm{M}$; SpPBP3, boronate 20 and 21 concentrations of $0.1-10 \mu \mathrm{M}$ and $1.0-50 \mu \mathrm{M}$, respectively, enzyme concentration of $104 \mathrm{nM}$, and substrate $K_{\mathrm{m}}$ of $350 \mu \mathrm{M}$. Competitive inhibition was assumed in fitting the data to a steady-state scheme. In a few cases, BsPBP4a with 11 and SpPBP3 with 20 and 21, boronate binding was slow (minutes) on a manual mixing time scale. Details of this will be published elsewhere. The $K_{\mathrm{i}}$ values listed in Table 3 represent the steady-state values.

\section{RESULTS AND DISCUSSION}

The LMM DD-peptidases examined in this work can be divided into two groups, one derived from E. coli, N. gonorrhoeae, Actinomadura R39, and B. subtilis, where the stem peptide has structure 22 with meso-diaminopimelic acid at position 3, and the other from $S$. pneumoniae, where the stem peptide has structure 23 with L-lysine at position 3 (Chart 1). ${ }^{a}$ Specifically, the LMMA enzymes studied were E. coli PBP5, N. gonorrhoeae PBP4, and S. pneumoniae PBP3, and the LMMC enzymes were the Actinomadura R39 DD-peptidase, N. gonorrhoeae PBP3, and B. subtilis PBP4a.

The panel of substrates and inhibitors 5-21 (Chart 2) was assembled for the examination of two major issues. The first of these is focused on the specificity of typical LMM DD-peptidases for extended acyl groups (acyl donor specificity), in particular to examine whether the in vivo substrate is likely to have a free amine at the $\mathrm{N}$-terminus of the acyl group as in $\mathbf{1}$ or whether its amine is acylated as in dimer or oligomer formation. ${ }^{2}$ The second point to be addressed is whether, for any of these enzymes, there is specificity for an extended (beyond D-Ala) leaving group, e.g., for 9 versus 5 or 16 versus 13. A narrow specificity for a D-Ala leaving group would presumably signal purely carboxypeptidase activity, whereas preference for an extended leaving group might rather indicate transpeptidase or endopeptidase activity; furthermore, one might expect that the preference for the extended leaving group by an endopeptidase would be more pronounced than for a transpeptidase where there must also be affinity for D-alanine. 
Chart 2

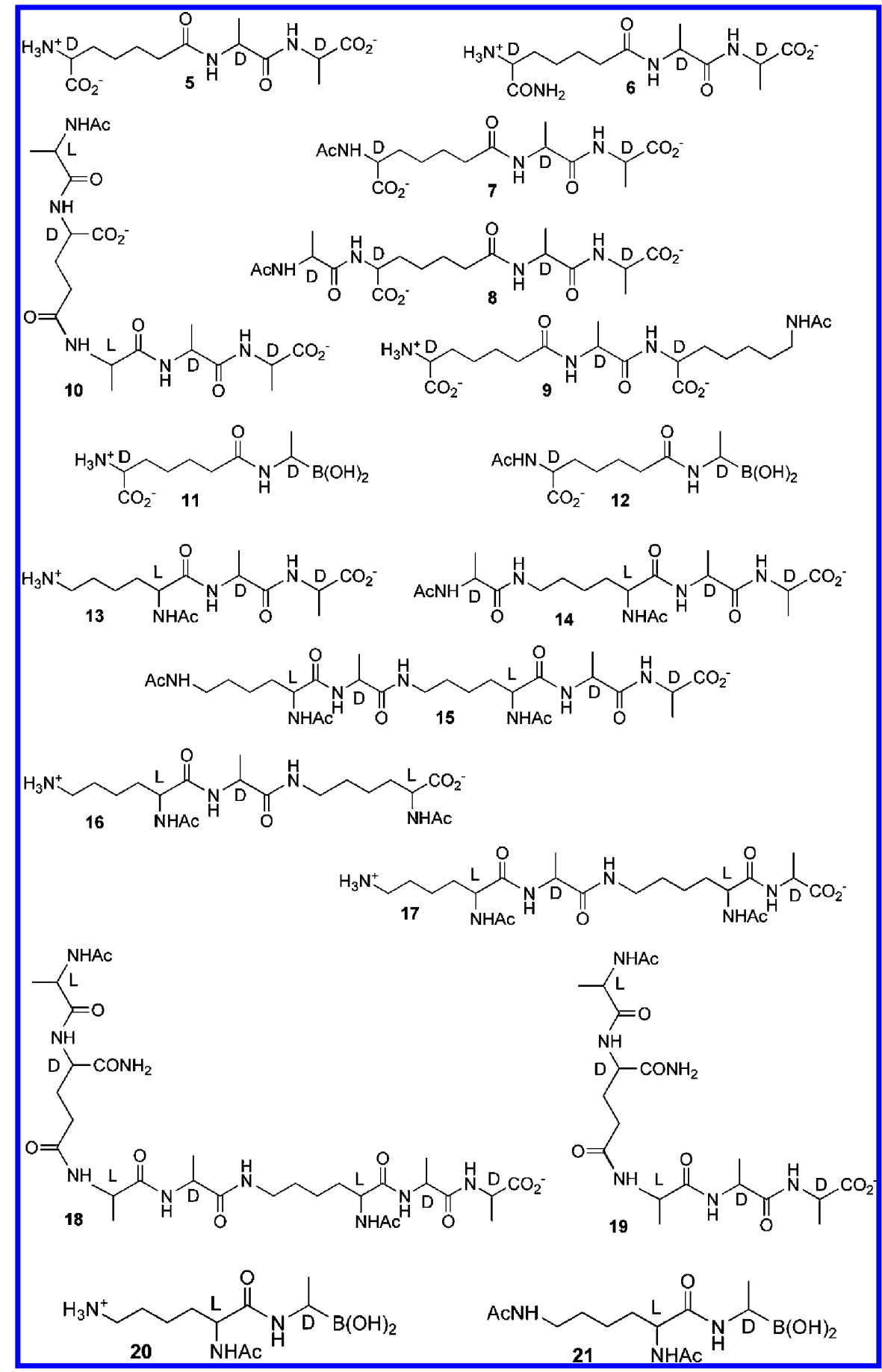

The boronates were prepared to investigate whether the affinity of these enzymes for elements of peptidoglycan structure could be detected through the stronger binding of transitionstate analogues compared to that of substrates. For example, these inhibitors might be more effective than substrates at inducing reactive conformations from inactive forms that may exist in solution

First, the response of the enzyme to $\mathrm{N}$-terminal acylation, such as would occur on expansion of monomer 1 to dimer 2 and to oligomers, was examined. The reactivity of the enzymes from bacteria with the $\mathrm{D}$ - $\alpha$-aminopimelyl stem peptide $\mathrm{N}$-terminus against peptides $7, \mathbf{8}$, and $\mathbf{1 0}$ (vs 5) and boronate 12 (vs 11) was assessed. Second, to evaluate the preference of the various enzymes for extension of the leaving group beyond D-alanine, as would occur in transpeptidase (actually, the preference for the nucleophile in the forward reaction, as depicted in $\mathbf{1}$ and 2) and endopeptidase reactions, peptide 9 (vs 5) was examined. The enzyme of $S$. pneumoniae, which has an $\varepsilon$-lysyl $\mathrm{N}$-terminus of the stem peptide, was evaluated analogously by reference to peptides $3,13-15,18$, and 19 (vs 13) and boronate 21 (vs 20). Preference for transpeptidase and endopeptidase (vs carboxypeptidase) activity was assessed by considering the results from peptides 16 and 17 (vs 13).

The products of hydrolysis of the peptides, as catalyzed by the enzymes named above, were identified by ${ }^{1} \mathrm{H}$ NMR experiments. Both the R39 DD-peptidase and BsPBP4a 
Table 1. Steady-State Parameters for Hydrolysis of Peptide Analogues of 22

\begin{tabular}{|c|c|c|c|c|c|c|}
\hline peptide & parameter $^{a}$ & R39 (LMMC) & BsPBP4a (LMMC) & NgPBP3 (LMMC) & EcPBP5 (LMMA) & NgPBP4 (LMMA) \\
\hline \multirow[t]{3}{*}{5} & $k_{\text {cat }}$ & $7.4^{b}$ & $\geq 22^{c}$ & $\geq 10$ & - & $\geq 0.9^{b}$ \\
\hline & $K_{\mathrm{m}}$ & $1.3 \times 10^{-3}$ & $\geq 1.0$ & $\geq 1.0$ & $\geq 1.0$ & $\geq 0.5$ \\
\hline & $k_{\text {cat }} / K_{\mathrm{m}}$ & $5.7 \times 10^{6}$ & $2.2 \times 10^{4}$ & $(1.0 \pm 0.1) \times 10^{4}$ & $\leq 100$ & $1.8 \times 10^{3}$ \\
\hline \multirow[t]{3}{*}{6} & $k_{\text {cat }}$ & $9.7 \pm 0.1$ & $\geq 30$ & $\geq 10$ & $\mathrm{ND}^{h}$ & $\mathrm{ND}^{h}$ \\
\hline & $K_{\mathrm{m}}$ & $(1.9 \pm 0.3) \times 10^{-2}$ & $\geq 1.0$ & $\geq 1.0$ & & \\
\hline & $k_{\mathrm{cat}} / K_{\mathrm{m}}$ & $5.2 \times 10^{5}$ & $(3.0 \pm 0.3) \times 10^{4}$ & $(3.0 \pm 0.1) \times 10^{3}$ & & \\
\hline \multirow[t]{3}{*}{7} & $k_{\text {cat }}$ & $\geq 0.8$ & $\geq 0.12$ & $\geq 10.6$ & - & $\geq 4.6$ \\
\hline & $K_{\mathrm{m}}$ & $\geq 2.0$ & $\geq 2.0$ & $\geq 2.0$ & $\geq 1.0$ & $\geq 2.0$ \\
\hline & $k_{\mathrm{cat}} / K_{\mathrm{m}}$ & $400 \pm 10$ & $62 \pm 1$ & $(5.3 \pm 0.1) \times 10^{3}$ & $\leq 100$ & $(2.3 \pm 0.1) \times 10^{3}$ \\
\hline \multirow[t]{3}{*}{8} & $k_{\text {cat }}$ & $\geq 0.64$ & $\geq 0.13$ & $\geq 2.0$ & - & $\geq 2.9$ \\
\hline & $K_{\mathrm{m}}$ & $\geq 2.0$ & $\geq 2.0$ & $\geq 2.0$ & $\geq 1.0$ & $\geq 2.0$ \\
\hline & $k_{\text {cat }} / K_{\mathrm{m}}$ & $340 \pm 10$ & $65 \pm 1$ & $(1.0 \pm 0.3) \times 10^{3}$ & $\leq 100$ & $(1.5 \pm 0.3) \times 10^{3}$ \\
\hline \multirow[t]{3}{*}{9} & $k_{\text {cat }}$ & $3.4 \pm 0.3$ & $\geq 5.8$ & $\geq 9.4$ & - & $\geq 2.9$ \\
\hline & $K_{\mathrm{m}}$ & $(1.7 \pm 0.3) \times 10^{-3}$ & $\geq 2.0$ & $\geq 2.0$ & $\geq 1.0$ & $\geq 2.0$ \\
\hline & $k_{\mathrm{cat}} / K_{\mathrm{m}}$ & $2.0 \times 10^{6}$ & $(2.9 \pm 0.1) \times 10^{3}$ & $(4.7 \pm 0.1) \times 10^{3}$ & $\leq 100$ & $(1.5 \pm 0.1) \times 10^{3}$ \\
\hline \multirow[t]{3}{*}{10} & $k_{\text {cat }}$ & $\geq 2.9^{b, d}$ & $\geq 0.116$ & $\geq 3.5^{b}$ & $\geq 0.15^{b}$ & - \\
\hline & $K_{\mathrm{m}}$ & $\geq 1.0$ & $\geq 1.0$ & $\geq 1.0$ & $\geq 1.0$ & $\geq 1.0$ \\
\hline & $k_{\mathrm{cat}} / K_{\mathrm{m}}$ & $(2.9 \pm 0.7) \times 10^{3}$ & $116 \pm 4$ & $3.5 \times 10^{3}$ & 150 & $\leq 100$ \\
\hline \multirow[t]{3}{*}{3} & $k_{\text {cat }}$ & $18.5^{e}$ & $\geq 6.6^{f}$ & $550^{g}$ & $\geq 0.22^{b}$ & $0.06^{b}$ \\
\hline & $K_{\mathrm{m}}$ & 0.28 & $\geq 1.0$ & 19 & $\geq 1.0$ & $\geq 1.0$ \\
\hline & $k_{\mathrm{cat}} / K_{\mathrm{m}}$ & $6.3 \times 10^{4}$ & $(6.6 \pm 0.2) \times 10^{3}$ & $2.9 \times 10^{4}$ & 220 & 60 \\
\hline
\end{tabular}

${ }^{a}$ Units of $k_{\text {cat }}, K_{\mathrm{m}}$, and $k_{\mathrm{cat}} / K_{\mathrm{m}}$ are $\mathrm{s}^{-1}, \mathrm{mM}$, and $\mathrm{s}^{-1} \mathrm{M}^{-1}$, respectively. ${ }^{b}$ From ref $34 .{ }^{c}$ From ref $53 .{ }^{d}$ This substrate is actually 16; the R39 stem peptide contains iGln rather than iGlu. ${ }^{e}$ From ref $75 .{ }^{f}$ The substrate here is actually $13 .{ }^{g}$ From ref $30 .{ }^{h}$ Not determined.

catalyzed cleavage of the C-terminal amino acid of 6-9. Hydrolysis of $\mathbf{5}$ by these enzymes is known to yield D-alanine from the C-terminus. ${ }^{34}$ Similarly, SpPBP3 was shown to catalyze a DD-carboxypeptidase reaction of 14, 15, 18, and 19 with release of D-Ala; under the same conditions, ${ }^{1} \mathrm{H}$ NMR and HPLC experiments showed no reaction of 16 and 17. Previous experiments have established that the R39 DD-peptidase, EcPBP5, NgPBP3, and NgPBP4 catalyze DD-carboxypeptidase reactions of 5-10, 3 , and 13. . $^{3,16,30,31}$

Steady-state kinetic studies of the hydrolysis of the peptides described above by the enzyme panel were conducted as described in Materials and Methods. The steady-state parameters obtained are listed in Tables 1 and 2. The steady-

Table 2. Steady-State Parameters for Hydrolysis of Peptide Analogues of 23 by $S$. pneumoniae PBP3 (LMMA)

\begin{tabular}{clll} 
peptide & $k_{\text {cat }}\left(\mathrm{s}^{-1}\right)$ & $K_{\mathrm{m}}(\mathrm{mM})$ & $k_{\text {cat }} / K_{\mathrm{m}}\left(\mathrm{s}^{-1} \mathrm{M}^{-1}\right)$ \\
$\mathbf{1 3}$ & $16 \pm 2$ & $1.8 \pm 0.5$ & $8.9 \times 10^{3}$ \\
3 & $\geq 6.2$ & $\geq 1$ & $(6.2 \pm 0.1) \times 10^{3}$ \\
$\mathbf{1 4}$ & $\geq 2$ & $\geq 1$ & $(2.0 \pm 0.1) \times 10^{3}$ \\
$\mathbf{1 5}$ & $\geq 0.92$ & $\geq 1$ & $(9.2 \pm 0.2) \times 10^{2}$ \\
$\mathbf{1 6}$ & - & - & 0 \\
17 & - & - & 0 \\
$\mathbf{1 8}$ & $7 \pm 1$ & $1.2 \pm 0.3$ & $6.0 \times 10^{3}$ \\
19 & $\geq 0.83$ & $\geq 1$ & $(8.3 \pm 0.2) \times 10^{2}$ \\
\hline
\end{tabular}

state boronate inhibition constants were also determined as described and are listed in Table 3.

LMMC DD-Peptidases. Commencing with the LMMC enzymes, we see that the R39 enzyme, as suggested by previously available data, ${ }^{26,27,34,35,39}$ has a clear preference for a nonacylated peptide $\mathrm{N}$-terminus, as seen in the $k_{\mathrm{cat}} / K_{\mathrm{m}}$ values of 5 and 9 versus 7,8 , and 10 and the much more potent inhibition of this enzyme by boronate 11 than by 12. The results, however, appear slightly ambiguous with respect to the transpeptidase/endopeptidase question. Peptide 9 is comparable to $\mathbf{5}$ in its reactivity with the enzyme, but not more so. On the other hand, it has been shown that extended acceptors such as $N$ - $\varepsilon$-acetyl-D-lysine are considerably better nucleophiles than D-alanine against the acyl-enzyme intermediate derived from 24, a thia analogue of 5. ${ }^{26}$ The analogous and arguably more peptidoglycan-mimetic peptide 25 was an even better nucleophile. These results were interpreted to indicate that the dominant role in activity of the R39 DD-peptidase is as an endopeptidase. ${ }^{26}$ Because the same transition state should be traversed in acylation of the enzyme by a peptide and aminolysis of the cognate acyl-enzyme intermediate by an amino acid, these results with $\mathbf{5}$ and $\mathbf{9}$ appear to some extent inconsistent with the earlier ones. The difference may come about because of the greater absolute reactivity of $\mathbf{5}$ and 9 $\left(k_{\mathrm{cat}} / K_{\mathrm{m}}=5.7 \times 10^{6}\right.$ and $2.0 \times 10^{6} \mathrm{~s}^{-1} \mathrm{M}^{-1}$, respectively $)$ compared to that of $25\left(k_{\text {cat }} / K_{\mathrm{m}}=7.3 \times 10^{4} \mathrm{~s}^{-1} \mathrm{M}^{-126}\right)$; the difference probably derives from the fact that $\mathbf{5}$ is more hydrophobic than $25 .^{40}$ It is possible that a physical step has taken over as the rate-determining step for the acylation by $\mathbf{5}$ (and 9), whereas for 25, the chemical step of acyl transfer is rate-determining. The simplest interpretation of the evidence mentioned above is that the optimal substrate of the R39 DD-peptidase would be a peptidoglycan fragment with a free $\mathrm{N}$-terminus but with an extended C-terminus, i.e., a dimer such as $\mathbf{2}$ or an oligomer. The preferred reaction catalyzed by the enzyme would be an endopeptidase reaction at the D-alanyl peptide bond closest to the free $\mathrm{N}$-terminus of a dimer, such as that represented by $\mathbf{2}$, or of an oligomer.
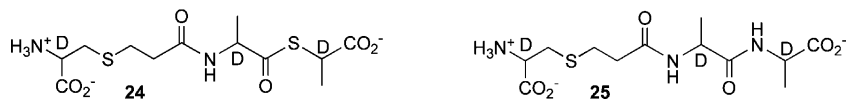

Crystal structures of substrate $\mathbf{5}$ and a transition-state analogue inhibitor 11 in complexes with the R39 DD-peptidase support the presence of a specific binding site for the free 
Table 3. Inhibition of DD-Peptidases by Boronates

\begin{tabular}{|c|c|c|c|c|}
\hline \multirow[b]{2}{*}{ enzyme } & \multicolumn{4}{|c|}{$K_{\mathrm{i}}(\mu \mathrm{M})$} \\
\hline & 11 & 12 & 20 & 21 \\
\hline R39 (LMMC) & $0.032 \pm 0.006$ & $70 \pm 15$ & $0.16 \pm 0.04$ & $-^{a}$ \\
\hline BsPBP4a (LMMC) & $0.0090 \pm 0.0002$ & $29.7 \pm 0.5$ & $-^{a}$ & $-{ }^{a}$ \\
\hline NgPBP3 (LMMC) & $13 \pm 3$ & $>1000$ & $-{ }^{a}$ & $-{ }^{a}$ \\
\hline EcPBP5 (LMMA) & $180 \pm 50$ & $250 \pm 30$ & $-^{a}$ & $-^{a}$ \\
\hline NgPBP4 (LMMA) & $2.2 \pm 0.4$ & $0.95 \pm 0.07$ & $-^{a}$ & $-^{a}$ \\
\hline SpPBP3 (LMMA) & $8.8 \pm 1.7$ & $-^{a}$ & $0.22 \pm 0.02$ & $0.91 \pm 0.04$ \\
\hline
\end{tabular}

N-terminus of a peptidoglycan fragment. ${ }^{27,39}$ The crystal structures show a well-defined binding site for a D- $\alpha$ aminopimelyl terminus. The important elements of the binding site are Tyr147 and Met414, which abut the hydrophobic tetramethylene chain, Asp142, which interacts strongly with the terminal ammonium ion, and Arg351 and Ser415, which interact with the ligand carboxylate. Finally, Trp139 appears to form a $\pi$-cation complex with the terminal ammonium ion. Thus, the kinetics and structural data appear to be in accord regarding the interaction of a peptidoglycan $\mathrm{N}$-terminus with the R39 DD-peptidase. The situation strongly resembles that found for the Streptomyces R61 DD-peptidase, described in the introductory section. ${ }^{18-21}$

An example in which the kinetics and structural data are apparently less in accord is the LMMC enzyme BsPBP4a. This enzyme is generally less reactive $\left(k_{\mathrm{cat}} / K_{\mathrm{m}}\right)$ with the relevant peptides than is the R39 DD-peptidase (Table 1 ). Its $k_{\text {cat }} / K_{\mathrm{m}}$ value for $\mathbf{5}$ is more than 100-fold lower than that of the R39 enzyme, which has a strikingly low $K_{\mathrm{m}}$ for this substrate; the $K_{\mathrm{m}}$ of 5 in the reaction with BsPBP4a is greater than $1 \mathrm{mM}$. Most directly, this would suggest much weaker interactions with and less specificity for the N-terminus than in the R39 case. Despite this, as for the R39 DD-peptidase, $k_{\text {cat }} / K_{\mathrm{m}}$ values for 7, 8, and 10 are considerably smaller than that of 5 , suggesting that the enzyme has little interest in an extended N-terminus. Similar to that of the R39 enzyme, the activity of BsPBP4a against 9 is slightly lower than against $\mathbf{5}$ but considerably higher than against 7 and 8, suggesting a reasonable affinity for an extended C-terminus and thus possible transpeptidase/endopeptidase activity.

More emphatically supporting the affinity of BsPBP4a for a free $\mathrm{N}$-terminus is the dramatically stronger inhibition demonstrated by boronate 11 than by 12 (Table 3). The apparent difference between the affinity of the enzyme for $\mathbf{1 1}$ and for the analogous substrate $\mathbf{5}$ is rather astonishing, even given that $\mathbf{1 1}$ is probably a transition-state analogue; for the R39 enzyme, the difference is much smaller because of the much stronger apparent binding (lower $K_{\mathrm{m}}$ ) of $\mathbf{5}$.

It thus may be that BsPBP4a is, like the R39 DD-peptidase, an endopeptidase, ${ }^{41}$ preferring a free $\mathrm{N}$-terminus adjacent to the cleavage site. In solution, however, it may exist in a largely inactive conformation (hence the high $K_{\mathrm{m}}$ values for $\mathbf{5}$ and 9) from which an active conformation can be induced only poorly by a specific substrate such as $\mathbf{5}$ or $\mathbf{9}$ or, more effectively, by a boronate transition-state analogue such as 11 (e.g., Scheme 2). It is interesting to note, in this regard, that the crystal structure of a complex of BsPBP4a with 5 shows the latter covalently attached to the active site serine as a D- $\alpha$-aminopimelyl-D-alanyl acyl-enzyme intermediate. ${ }^{42}$ This certainly suggests the trapping of the substrate by an inactive conformation. An acyl-enzyme intermediate has also been observed in a crystal structure of $S$. pneumoniae PBP1b, although in this case, the substrate was nonspecific. ${ }^{43}$ It might also be noted that the association of boronate $\mathbf{1 1}$ with BsPBP4a is an at least twophase process with a slower phase lasting for minutes. The $K_{\mathrm{i}}$ quoted in Table 3 is the steady-state value achieved after completion of the transient phase. Details of this reaction will be published elsewhere, but it is possible that this observation also derives from enzyme isomerization. The binding of 11 to the R39 DD-peptidase shows only a single phase on the same manual mixing time scale.

\section{Scheme 2}
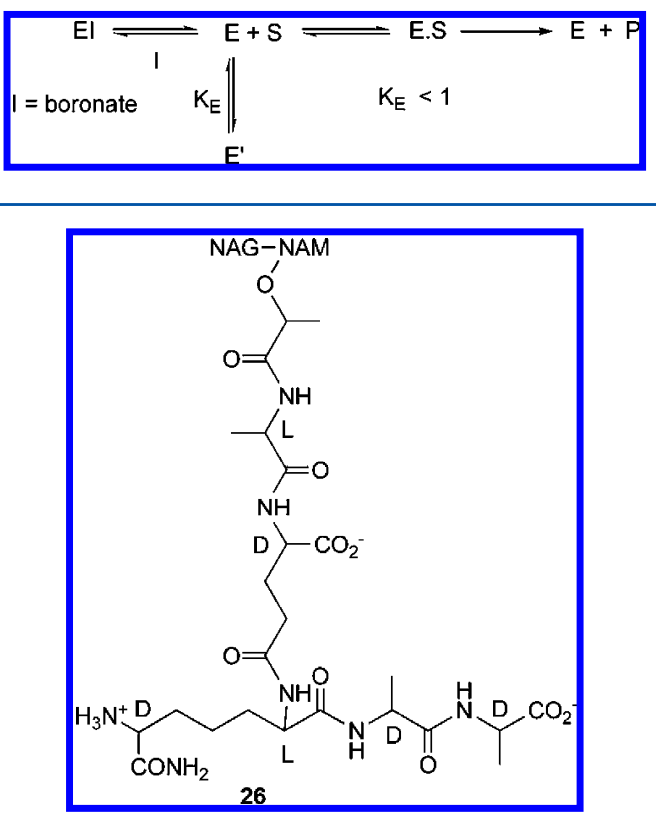

Another complicating factor with respect to $\mathrm{BsPBP} 4 \mathrm{a}$ is that some $99 \%$ of peptidoglycan in vegetative cells of B. subtilis have the free carboxyl group of the diaminopimelyl residue amidated; i.e., the stem peptide has the structure of $26 .{ }^{44,45}$

It was possible, therefore, that the poor affinity of $\mathbf{5}$ for BsPBP4a reflected the specificity of the binding site for an amide $\mathrm{CONH}_{2}$ group, rather than a carboxylate. We therefore prepared peptide 6 , the amidated analogue of 5 , and examined its reactivity with the relevant enzymes (Table 1). Substrate 6 was $\sim 1$ order of magnitude less reactive $\left(k_{\text {cat }} / K_{\mathrm{m}}\right)$ with the R39 DD-peptidase, mainly because of a larger $K_{\mathrm{m}}$ value, and also with NgPBP3. This result may reflect the ability of the amide group to adapt to the polar residues of the carboxylate binding site and the absence of any need for these enzymes to strongly discriminate between carboxylate and amide because they, presumably, would be unlikely to interact with the latter in vivo. 
The kinetics of the reaction between BsPBP4a and 6 are also interesting. The $k_{\mathrm{cat}} / K_{\mathrm{m}}$ value for $\mathbf{6}$ is essentially the same as for 5, with no sign of enhanced (or weakened) binding. It is likely that BsPBP4a does encounter free pimelyl carboxylates as well as amides, and thus, a versatile binding site may be advantageous. Although the role of BsPBP4a in vivo is not known, it is apparently expressed in late vegetative stages ${ }^{46}$ when spore formation may be beginning; it has also been reported that the aminopimelyl carboxyl of B. subtilis spore peptidoglycan is not amidated. ${ }^{47}$

The picture presented by NgPBP3, another LMMC enzyme, in Table 2 is rather different from that of the enzymes described above. This enzyme exhibits no particularly notable specificity toward any of the structural motifs presented by the relevant peptides. Apparent binding $\left(K_{\mathrm{m}}\right)$ to the enzyme is also uniformly weak. It seems that this enzyme may be able to nonspecifically catalyze all three reactions, carboxypeptidase, transpeptidase and endopeptidase, with comparable facility and on any substrate. These data, therefore, taken alone, could be interpreted in terms of a versatile, nonspecific enzyme that can undertake any task presented to it, but the presence of such an enzyme in the carefully regulated process of bacterial cell wall metabolism ${ }^{1,2,48,49}$ seems unlikely, unless it could be selectively regulated through its location and interaction with other ligands. Gutheil and co-workers ${ }^{30,50}$ have shown that this enzyme is much more effective against L- $\alpha$-lysyl-D-alanyl-Dalanine peptides where the lysine amine groups are acylated by quite large hydrophobic moieties, e.g., tert-butyloxycarbonyl and benzyloxycarbonyl. It is not evident how these substituents directly relate to peptidoglycan structure, but a possible interpretation is that these substituents serve to reduce the mobility of the enzyme-substrate complex, leading, by entropic advantage, to more effective catalysis. This rationale would suggest that in vivo, $\mathrm{NgPBP} 3$ may function in a space more congested than that of the R39 and BsPBP4a enzymes. Such congestion could be caused by its restriction to the membrane and its proximity to other proteins, peptidoglycan, or both. NgPBP3 and BsPBP4a may be membrane-associated ${ }^{30,46}$ even though they do not have a terminal peptide for membrane attachment as do the typical LMMA and HMM enzymes. In this regard, however, it is worth noting that NgPBP3 derives from a Gram-negative bacterium while the R39 DD-peptidase and BsPBP4a derive from Gram-positive organisms. The site of activity of these enzymes may differ in character, depending on this division. Under this scenario, one would expect that in vivo, the absolute reactivity of the peptide elements of peptidoglycan would be enhanced relative to the results in Table 2 , again through entropic advantages. With respect to substrate specificity, it may be that, as for BsPBP4a, the much stronger preference of $\mathrm{NgPBP} 3$ for the $\mathrm{N}$-terminal-free boronate 11 than for the $\mathrm{N}$-acylated $\mathbf{1 2}$ is the most relevant result, again pointing to a class $\mathrm{C}$ specificity for a free $\mathrm{N}$-terminus.

Prior to concluding this discussion of the LMMC enzymes, we find it is useful to note that a quite strong similarity does exist between the putative (established for the R39 DDpeptidase and BsPBP4a) peptide $\mathrm{N}$-terminus binding sites (Table 4, where the relevant data for four LMMC enzymes are given). As well as for the three enzymes discussed above, data for EcPBP4 are also given. This is a well-established LMMC PBP where a crystal structure is available, ${ }^{51}$ although not with the enzyme bound to a peptidoglycan-mimetic peptide. It seems that the $\mathrm{D}$ - $\alpha$-aminopimelyl-binding site is well-conserved in all of these enzymes. Asp142 of the R39
Table 4. N-Terminal Binding Site in LMMC PBPs

\begin{tabular}{ccccc}
\multicolumn{1}{c}{ R39 } & BsPBP4a & NgPBP3 & EcPBP4 & interaction with 5 \\
Trp139 & Pro142 & Pro152 & Phe147 & $\mathrm{NH}_{3}{ }^{+}$ \\
Asp142 & Asp145 & Asp155 & Asp150 & $\mathrm{NH}_{3}{ }^{+}$ \\
Tyr147 & Tyr150 & Phe160 & Phe155 & $\left(\mathrm{CH}_{2}\right)_{3}$ \\
Arg351 & His352 & Arg361 & Arg352 & $\mathrm{CO}_{2}{ }^{-}$ \\
Met414 & Leu415 & Leu421 & Leu408 & $\left(\mathrm{CH}_{2}\right)_{3}$ \\
Ser415 & Ser416 & Gln422 & Asn409 & $\mathrm{CO}_{2}{ }^{-}$ \\
\hline
\end{tabular}

DD-peptidase is fully conserved; Arg351, or the alternative, potentially cationic, His352 of $\mathrm{BsPBP} 4 \mathrm{a}$, is conserved, and hydrophobic residues corresponding to Tyr147 and Met414 of the R39 DD-peptidase are retained. Trp139, the putative $\pi$-donor of R39 to the cationic ammonium terminus, is not strictly conserved and is replaced with the less electron-rich Phe and Pro in the other enzymes. Finally, Ser415 is replaced with Gln or Asn in two of the enzymes; the backbone carbonyl of this residue, which appears to hydrogen bond to the ligand in both the R39 and BsPBP4a crystal structures, ${ }^{27,42}$ is, of course, retained, and polar interactions of the ligand with the terminal amide groups of Gln and Asn are certainly possible. The crystal structure of the BsPBP4a-5 complex ${ }^{42}$ shows the $\mathrm{N}$-terminus of the substrate bound to the enzyme in much the same way as in the R39 DD-peptidase, but with His352 directly replacing Arg351. Therefore, despite some counterindications from the peptide hydrolysis kinetics, but in accord with the specific binding of boronate 11, it does seem likely that the R39 DDpeptidase, BsPBP4a, NgPBP3, and, quite likely, on the basis of the conservation of the substrate binding motif illustrated by Table 4, all LMMC enzymes have a specific binding site for the free N-terminus of the cognate stem peptide. A FASTA search showed that the 500 proteins of the UniProtKP database most similar to the R39 DD-peptidase retain homologues of Asp142 and Arg/His351. This high degree of active site similarity may be partly obscured in peptide hydrolysis kinetics in vitro by the presence of unreactive enzyme conformations in solution.

LMMA DD-Peptidases. The class A enzymes examined responded less positively, in general, to variations in substrate structure than the class $\mathrm{C}$ enzymes. EcPBP5 reacted very slowly with the generic $\mathrm{N}$-terminally acylated peptide $\mathbf{3}$ and with $\mathbf{1 0}$ but not detectably with 7-9. Boronates 11 and 12 were also relatively ineffective as inhibitors, and no real sign of specificity for either of them was observed.

This result is not entirely unexpected. As previously noted, solubilized E. coli PBP5 rests in an active site-distorted conformation in the crystalline solid state, and, most likely, also in membranes ${ }^{52}$ and in solution. ${ }^{35}$ It is pertinent to note at this point that a nonspecific boronate has been shown to induce organization of the reaction center, ${ }^{53}$ but this boronate did not have a peptidoglycan-mimetic side chain; thus, no direct evidence about how a specific side chain might bind was obtained. These results indicate that none of the structural motifs in the substrates tested was able to induce a catalytically effective conformation. As discussed above for NgPBP3, however, we presume that this induction does occur in vivo. There is evidence that very specific attachment of EcPBP5 to the cell membrane is required for activity in vivo. ${ }^{54}$ Recent experiments suggest that not only membrane attachment but also "ongoing peptidoglycan synthesis" may be needed for strong EcPBP5 substrate binding and catalysis. ${ }^{55}$ This is all certainly suggestive of the presence of a specific environment in vivo very different from that in vitro. 
NgPBP4 is a likely orthologue (25.5\% identical, $59.6 \%$ similar, 255-residue overlap; Lalign ${ }^{56}$ ) of EcPBP5 in another Gram-negative bacterium. It shows more reactivity $\left(k_{\text {cat }} / K_{\mathrm{m}}\right)$, in general, with the peptide panel than the $E$. coli enzyme does but still not significant affinity $\left(K_{\mathrm{m}}\right)$ for any particular peptide (Table 1). The enzyme is comparably reactive with the N-terminally extended peptides 7, 8, and $\mathbf{1 0}$ as with $\mathbf{5}$, the peptide with the free $\mathrm{N}$-terminus. These results are in accord with those from boronate inhibition (Table 3) where NgPBP4 shows greater affinity for $\mathbf{1 1}$ and $\mathbf{1 2}$ than does EcPBP5, but no discrimination between the two. NgPBP4 also appears as unenthusiastic about an extended leaving group [e.g., peptide 9 (Table 1)] as for the extended N-terminus. This pattern of reactivity rather mirrors that of $\mathrm{NgPBP} 3$, although $\mathrm{NgPBP} 3$ and $\mathrm{NgPBP} 4$ are structurally quite different enzymes from different subgroups. Boronates 11 and 12, however, give no evidence of a strong $\mathrm{N}$-terminal specificity of $\mathrm{NgPBP} 4$ as they do for NgPBP3. It is interesting to note here that the amino acid sequence of $\mathrm{NgPBP} 4$ is more similar to that of EcPBP7 (42.9\% identical, 240-residue overlap; Lalign ${ }^{56}$ ) than that of EcPBP5, and EcPBP7 is thought to be an endopeptidase; ${ }^{57}$ perhaps PBP4 in N. gonorrhoeae covers the roles of both PBP5 and PBP7 in E. coli.

SpPBP3 is similar to NgPBP4 in general reactivity with peptides, although slightly different in detail (Table 2). This enzyme is also a member of the LMMA group but, as noted above, is derived from a Gram-positive organism with a stem peptide containing lysine ${ }^{23}$ rather than diaminopimelic acid. ${ }^{22}$ Although SpPBP3 does not show high affinity for any of the group of peptides 14-19, it does have comparable reactivity with 13, the peptide with the free $\mathrm{N}$-terminus, as with the N-terminally extended peptides $14,15,18$, and 19 , where the latter two contain a significant number of the elements of a peptidoglycan dimer. The presence of this extended $\mathrm{N}$-acylation in 18 and 19 does not enhance the reactivity of the peptide or its affinity for the enzyme. SpPBP3 does, however, show distinct aversion to extended leaving group peptides 16 and 17, thus displaying the distinct signature of a carboxypeptidase (unlike NgPBP4).

SpBPB3 does bind boronates 20 and $\mathbf{2 1}$ quite tightly but shows little discrimination between them. Thioesters are also substrates of LMMA enzymes, but little substrate specificity with respect to peptidoglycan structure has been noticed, e.g., with SpPBP3 (K. S. Sarkar and R. F. Pratt, unpublished observations).

Structurally, SpPBP3 is similar to EcPBP5, with the same protein fold, but there are some differences in detail. ${ }^{33}$ In the DD-peptidase domain, these differences appear in loops surrounding the active site. In particular, the " $\Omega$-like" loop in SpPBP3, comprising residues 156-181, is much larger than the corresponding loop, spanning residues 147-158, in EcPBP5. ${ }^{33}$ SpPBP3 also has a six-amino acid insertion downstream of the KTG motif of the active site. Morlot et al. ${ }^{33}$ suggested that these differences may distinguish enzymes such as EcPBP5 that interact with peptidoglycan-bearing diaminopimelic acid as the third residue of the stem peptide ${ }^{22}$ from those, such as SpPBP3, that bear lysine as this residue. ${ }^{23}$ The extended structure in the latter case might indicate that the terminus of the stem peptide may directly interact with the protein, although no crystal structure showing this has been published. The peptide hydrolysis kinetics and boronate binding, described above, however, do not support this idea, at least in dilute aqueous solution.

PBP6 of E. coli is very similar in structure to EcPBP5. These enzymes share considerable sequence similarity (60.2\% identical,
$85.6 \%$ similar, 387-residue overlap ${ }^{56}$ ), although the role of PBP6 in vivo may be different from that of PBP5. ${ }^{58-61}$ A crystal structure of PBP6 has recently been described and, notably, also one with an extended stem peptide analogue bound. ${ }^{62} \mathrm{~A}$ striking feature of the latter structure is that the N-terminus of the peptide (lysine) does not interact with the protein at all and extends directly out into solution. The structure is certainly in accord with the kinetic results for EcPBP5 in this paper, if it is assumed that a complex of an analogous peptide with EcPBP5 would have a similar structure. There is also little evidence of strong productive interaction between EcPBP5 or EcPBP6 and the NAG-NAM sugars of the peptidoglycan monomer. ${ }^{62,63} \mathrm{~A}$ crystal structure of a complex of PBP5 with a $\beta$-lactam bearing a $D$ - $\alpha$-aminopimelyl side chain showed the side chain to be so mobile that it cannot be observed. ${ }^{39}$ One possibility is that, in vivo, the extended $\mathrm{N}$-terminus interacts with either the peptidoglycan or another protein, which then induces specificity. There does not appear to be convincing evidence of complexes of EcPBP5 with other PBPs or cell cycle proteins, ${ }^{2}$ although there is a report of a complex among PBP1b, PBP2, PBP4, and PBP5, isolated by chemical cross-linking, in Haemophilus influenzae, another Gram-negative bacterium. ${ }^{64}$

\section{CONCLUSIONS}

The results described above tend to divide the LMM DDpeptidases into three groups on the basis of their behavior toward peptidoglycan-mimetic ligands. First, the soluble LMMB and LMMC enzymes, the R61 and R39 DD-peptidases, respectively, can be distinguished from a pair of LMMC enzymes, BsPBP4a and NgPBP3. The latter pair, like the former, apparently has a well-defined and specific binding site for a peptidoglycan-mimetic substrate, but unlike with the former group, its presence is not reflected in substrate turnover kinetics in vitro. The latter enzymes are, however, inhibited strongly and specifically by a peptidoglycan-mimetic boronate. This transition-state analogue apparently has the ability to induce peptidoglycan specificity in the enzyme active site. Finally, the LMMA enzymes, EcPBP5, NgPBP4, and SpPBP3, show no marked affinity for peptidoglycan-mimetic substrates or boronate inhibitors, and thus, these ligands are unable to induce a specific active site structure under the conditions employed. Crystal structures have not, to date, revealed a specific binding site on these enzymes beyond that accommodating D-alanyl-D-alanine. ${ }^{62}$ Although the details of the in vivo function of all of the enzymes mentioned above are not well understood, it is interesting to note that the soluble enzymes have no defined role in peptidoglycan synthesis and maintenance while the membrane- bound/associated enzymes have at least tentatively assigned roles. ${ }^{2,48}$

One thus gets the impression that a number of these enzymes are present in solution in less than optimally specific and/or reactive conformations and that these cannot efficiently be induced into specific or reactive forms by small peptidoglycanmimetic peptide fragments. In some cases (LMMC), although not in others (LMMA), they can be so induced by tighter binding transition-state analogues. A crystal structure of one of the LMMC enzymes, currently available in apo form (e.g., BsPBP4a), bound to a specific boronate would thus be of considerable interest. $\beta$-Lactams, transition-state analogues themselves, ${ }^{65}$ are also able to induce reactivity with many of these enzymes. One must conclude that the in vivo environment must also be able to induce specific activity by interactions yet unknown. The same conclusion applies to HMM PBPs, which, 
as solubilized forms in vitro, also do not in general turn over small peptidoglycan-mimetic substrates at rates sufficient to support bacterial growth; ${ }^{34,35,66}$ larger model substrates may be needed. ${ }^{67,68}$ There is some evidence of alternative conformations of particular HMM PBPs from crystal structures ${ }^{69-71}$ and solution studies. ${ }^{72-74}$ It is thus clear that an understanding of the molecular details of catalysis in vivo by the most important of these enzymes has not yet been achieved.

\section{ASSOCIATED CONTENT}

\section{S Supporting Information}

Synthetic details for the preparation of peptides 6-9 and boronates 12, 20, and 21. This material is available free of charge via the Internet at http://pubs.acs.org.

\section{AUTHOR INFORMATION}

\section{Corresponding Author}

*Telephone: (860) 685-2629. E-mail: rpratt@wesleyan.edu. Fax: (860) 685-2211.

\section{Funding}

This research was supported by National Institutes of Health Grants AI-17986 (R.F.P.) and AI-36901 (R.A.N.). C.D. is chercheur Qualifié of the fonds National de la Recherche Scientifique (FRS-FNRS, Brussels, Belgium). The work in Liège was supported by the Belgian Program on Interuniversity Poles of Attraction initiated by the Belgian State, Prime Minister's Office, Science Policy Programming (PAI 6/19).

\section{ACKNOWLEDGMENTS}

We are grateful to Dr. Andrea Dessen of the Institut de Biologie Structurale (Grenoble, France) for the sample of SpBP3 and for a careful reading of the manuscript.

\section{ABBREVIATIONS}

BsPBP4a, B. subtilis penicillin-binding protein 4a; EcPBP5, E. coli penicillin-binding protein 5; HMM, high-molecular mass; LMM, low-molecular mass; NAG, $N$-acetylglucosamine; NAM, $\mathrm{N}$-acetylmuramic acid; NgPBP3 and NgPBP4, N. gonorrhoeae penicillin-binding proteins 3 and 4, respectively; NMR, nuclear magnetic resonance; SpPBP3, S. pneumoniae penicillin-binding protein 3.

\section{ADDITIONAL NOTE}

${ }^{a}$ It should be noted that peptidoglycan in $S$. pneumoniae typically contains both unbridged (direct D-Ala- $\varepsilon$-L-Lys) and bridged (D-Ala-L-Ala-L-Ser- $\varepsilon$-L-Lys) or (D-Ala-L-Ala-L-Ala- $\varepsilon$-LLys) cross-links; in wild-type strains, $>50 \%$ of the N-termini are simply L-Lys. ${ }^{36-38}$ The elaborated $\mathrm{N}$-termini are found to predominate in $\beta$-lactam-resistant strains. $S$. pneumoniae transpeptidases must therefore catalyze nucleophilic attack on an acyl-enzyme intermediate by the $\varepsilon$-amine of lysine and also by the terminal $\alpha$-amine of an L-Ala peptide, the latter in an interesting and, as yet, not well-characterized DL-transpeptidase reaction. This paper deals with the former reaction, expected to be catalyzed by "wild-type" transpeptidases, but not the latter.

\section{REFERENCES}

(1) Höltje, J.-V. (1998) Growth of the stress-bearing and shapemaintaining murein sacculus of Escherichia coli. Microbiol. Mol. Biol. Rev. 62, 181-203.
(2) Vollmer, W., and Bertsche, U. (2007) Murein (peptidoglycan) structure, architecture and biosynthesis in Escherichia coli. Biochim. Biophys. Acta 1788, 1714-1733.

(3) Joris, B., and Frère, J.-M. (1988) Penicillin-sensitive enzymes in peptidoglycan biosynthesis. CRC Crit. Rev. Microbiol. 11, 299-396.

(4) Hackenbeck, R, and Coyette, J. (1998) Resistant penicillinbinding proteins. Cell. Mol. Life Sci. 54, 332-340.

(5) Barlow, M. (2009) What antimicrobial resistance has taught us about horizontal gene transfer. Methods Mol. Biol. 532, 397-411.

(6) Pinho, M. G., de Lencastre, H., and Tomasz, A. (2001) An acquired and a native penicillin-binding protein cooperate in building the cell wall of drug-resistant staphylococci. Proc. Natl. Acad. Sci. U.S.A. 98, 10886-10891.

(7) Spratt, B. G. (1994) Resistance to antibiotics mediated by target alterations. Science 264, 388-393.

(8) Reinert, R. R. (2009) The antibiotic resistance profile of Streptococcus pneumoniae. Clin. Microbiol. Infect. 15 (Suppl. 3), 7-11.

(9) Fontana, R., Aldegheri, M., Ligozzi, M., Lopez, H., Sucari, R., and Satta, G. (1994) Overproduction of a low-affinity penicillin-binding protein and high-level ampicillin resistance in Enterococcus faecium. Antimicrob. Agents Chemother. 38, 1980-1983.

(10) Lindberg, R., Fredlund, H., Nicholas, R. and Unemo, M. (2007) Neisseria gonorrhoeae isolates with reduced susceptibility to cefixime and ceftriaxone: Association with genetic polymorphisms in penA, mtrR, porB1b, and ponA. Antimicrob. Agents Chemother. 51, 2117-2122.

(11) Page, M. G. P. (2007) Ceftobiprole: A case study. Expert Opin. Drug Discovery 2, 115-129.

(12) Shahid, M., Sobia, F., Singh, A., Malik, A., Khan, H. M., Jonas, D., and Hawkey, P. M. (2009) $\beta$-Lactams and $\beta$-lactamase inhibitors in current or potential clinical practice: A comprehensive update. Crit. Rev. Microbiol. 35, 81-108.

(13) Ghuysen, J.-M. (1991) Serine $\beta$-lactamases and penicillinbinding proteins. Annu. Rev. Microbiol. 45, 37-67.

(14) Popham, D. L., and Young, K. D. (2003) Role of penicillinbinding proteins in bacterial cell morphogenesis. Curr. Opin. Microbiol. 6, 594-599.

(15) Ghosh, A. S., Chowdhury, C., and Nelson, D. E. (2008) Physiological functions of D-alanine carboxypeptidases in Escherichia coli. Trends Microbiol. 16, 309-317.

(16) Ghuysen, J.-M., Frère, J.-M., Leyh-Bouille, M., Coyette, J., Dusart, J., and Nguyen-Distèche, M. (1979) Use of model enzymes in determination of the mode of action of penicillins and $\Delta 3$ cephalosporins. Annu. Rev. Biochem. 48, 73-101.

(17) Adam, M., Damblon, C., Plaitin, B., Christiaens, L., and Frère, J.-M. (1990) Chromogenic depsipeptide substrates for $\beta$-lactamases and penicillin-sensitive DD-peptidases. Biochem. J. 270, 525-529.

(18) Anderson, J. W., and Pratt, R. F. (2000) Dipeptide binding to the extended active site of the Streptomyces R61 D-alanyl-D-alanine peptidase: The path to a specific substrate. Biochemistry 39, 1220012209.

(19) McDonough, M. A., Anderson, J. W., Silvaggi, N. R., Pratt, R. F., and Kelly, J. A. (2002) Structures of two kinetic intermediates reveal species specificity of penicillin-binding proteins. J. Mol. Biol. 322, 111122.

(20) Kumar, I., and Pratt, R. F. (2005) Transpeptidation reactions of a specific substrate catalyzed by the Streptomyces R61 DD-peptidase: The structural basis of acyl acceptor specificity. Biochemistry 44, 99619970.

(21) Kumar, I., and Pratt, R. F. (2005) Transpeptidation reactions of a specific substrate catalyzed by the Streptomyces R61 DD-peptidase: Characterization of a chromogenic substrate and acyl acceptor design. Biochemistry 44, 9971-9979.

(22) Rhazi, N., Delmarcelle, M., Sauvage, E., Jacquemotte, F., Devriendt, K., Tallon, V., Ghosez, L., and Frère, J.-M. (2005) Specificity and reversibility of the transpeptidation reaction catalyzed by the Streptomyces R61 D-Ala-D-Ala peptidase. Protein Sci. 14, 29222928. 
(23) Leyh-Bouille, M., Nakel, M., Frère, J.-M., Johnson, K., Ghuysen, J.-M., Nieto, M., and Perkins, H. R. (1972) Penicillin-sensitive DDcarboxypeptidases from Streptomyces strains R39 and K11. Biochemistry 11, 1290-1298.

(24) Ghuysen, J.-M., Leyh-Bouille, M., Campbell, J. N., Moreno, R., Frère, J.-M., Duez, C., Nieto, M., and Perkins, H. R. (1973) Structure of the wall peptidoglycan of Streptomyces R39 and the specificity profile of its exocellular DD-carboxypeptidase-transpeptidase for peptide acceptors. Biochemistry 12, 1243-1251.

(25) Ghuysen, J.-M., Reynolds, P. E., Perkins, H. R., Frère, J.-M., and Moreno, R. (1974) Effects of donor and acceptor peptides on concomitant hydrolysis and transfer reactions catalyzed by the exocellular DD-carboxypeptidase-transpeptidase from Streptomyces R39. Biochemistry 13, 2539-2547.

(26) Adediran, S. A., Kumar, I., Nagarajan, R., Sauvage, E., and Pratt, R. F. (2011) Kinetics of reactions of the Actinomadura R39 DDpeptidase with specific substrates. Biochemistry 50, 376-387.

(27) Dzhekieva, L., Rocaboy, M., Kerff, F., Charlier, P., Sauvage, E., and Pratt, R. F. (2010) Crystal structure of a complex between the Actinomadura R39 DD-peptidase and a peptidoglycan-mimetic boronate inhibitor: Interpretation of a transition state analogue in terms of catalytic mechanism. Biochemistry 49, 6411-6419.

(28) Sauvage, E., Herman, R., Petrella, S., Duez, C., Bouillenne, F., Frère, J.-M., and Charlier, P. (2005) Crystal structure of the Actinomadura R39 DD-peptidase reveals new domains in penicillin binding proteins. J. Biol. Chem. 280, 31249-31256.

(29) Nicholas, R. A., Krings, S., Tomberg, J., Nichola, G., and Davies, C. (2003) Crystal structures of wild-type penicillin-binding protein 5 from Escherichia coli. J. Biol. Chem. 278, 52826-52833.

(30) Stevanova, M. E., Tomberg, J., Olesky, M., Höltje, J.-V., Gutheil, W. G., and Nicholas, R. A. (2003) Neisseria gonorrhoeae penicillinbinding protein 3 exhibits exceptionally high carboxypeptidase and $\beta$-lactam binding activities. Biochemistry 42, 14614-14625.

(31) Stefanova, M. E., Tomberg, J., Davies, C., Nicholas, R. A., and Gutheil, W. G. (2004) Overexpression and enzymatic characterization of Neisseria gonorrhoeae penicillin-binding protein 4. Eur. J. Biochem. $271,23-32$.

(32) Duez, C., Van Hove, M., Gallet, X., Bouillene, F., Docquier, J.-D., Brous, A., and Frère, J.-M. (2001) Purification and characterization of PBP4a, a new low molecular-weight penicillin-binding protein from Bacillus subtilis. J. Bacteriol. 183, 1595-1599.

(33) Morlot, C., Pernot, L., Le Gouellec, A., Di Giulmi, A. M., Vernet, T., Dideberg, O., and Dessen, A. (2005) Crystal structure of a peptidoglycan synthesis regulatory factor (PBP3) from Streptococcus pneumoniae. J. Biol. Chem. 280, 15984-15991.

(34) Anderson, J. W., Adediran, S. A., Charlier, P., Nguyen-Distèche, M., Frère, J.-M., Nicholas, R. A., and Pratt, R. F. (2003) On the substrate specificity of bacterial DD-peptidases: Evidence from two series of peptidoglycan-mimetic peptides. Biochem. J. 373, 949-955.

(35) Josephine, H. R., Charlier, P., Davies, C., Nicholas, R. A., and Pratt, R. F. (2006) Reactivity of penicillin-binding proteins with peptidoglycan-mimetic $\beta$-lactams: What's wrong with these enzymes? Biochemistry 45, 15873-15883.

(36) Garcia-Bustos, J. F., Chait, B. T., and Tomasz, A. (1987) Structure of the peptide network of pneumococcal peptidoglycan. J. Biol. Chem. 262, 15400-15405.

(37) Severin, A., and Tomasz, A. (1996) Naturally occurring peptidoglycan variants of Streptococcus pneumoniae. J. Bacteriol. 178, $168-174$.

(38) Tomasz, A., and Fischer, W. (2006) The cell wall of Streptococcus pneumoniae. In Gram-positive Pathogens (Fischetti, V. A., Novick, R. P., Ferretti, J. J., Portnoy, D. A., and Rood, J. I., Eds.) 2nd ed., pp 230-240, American Society for Microbiology Press, Washington, DC.

(39) Sauvage, E., Powell, A. J., Heilemann, J., Josephine, H. R., Charlier, P., Davies, C., and Pratt, R. F. (2008) Crystal structures of complexes of bacterial DD-peptidases with peptidoglycan-mimetic ligands; the substrate specificity puzzle. J. Mol. Biol. 381, 383-393.
(40) Nagarajan, R., and Pratt, R. F. (2004) Synthesis and evaluation of new substrate analogues of Streptomyces R61 DD-peptidase: Dissection of a specific ligand. J. Org. Chem. 69, 7472-7478.

(41) Duez, C., Zervosen, A., Teller, N., Melkonian, R., Banzubazé., Bouillenne, F., Luxen, A., and Frère, J.-M. (2009) Characterization of the proteins encoded by the Bacillus subtilis yoxA-dacC operon. FEMS Microbiol. Lett. 300, 42-47.

(42) Sauvage, E., Duez, C., Herman, R., Kerff, F., Perrella, S., Anderson, J. W., Adediran, S. A., Pratt, R. F., Frère, J.-M., and Charlier, P. (2007) Crystal structure of the Bacillus subtilis penicillin-binding protein $4 \mathrm{a}$ and its complex with peptidoglycan-mimetic peptide. J. Mol. Biol. 371, 528-539.

(43) Macheboeuf, P., Lemaire, D., Dos Santos Martins, A., Dideberg, O., Jamin, M., and Dessen, A. (2008) Trapping of an acyl-enzyme intermediate in a penicillin binding protein (PBP)-catalyzed reaction. J. Mol. Biol. 376, 405-413.

(44) Atrih, A., Bacher, G., Allmaier, G., Williamson, M. P., and Foster, S. J. (1999) Analysis of peptidoglycan structure from vegetative cells of B. subtilis 168 and role of PBP5 in peptidoglycan maturation. J. Bacteriol. 181, 3956-3966.

(45) Warth, A. D., and Strominger, J. L. (1971) Structure of the peptidoglycan from vegetative cell walls of Bacillus subtilis. Biochemistry 10, 4349-4358.

(46) Pederson, L. B., Murray, T., Popham, D. L., and Setlow, P. (1998) Characterization of $\mathrm{dacC}$, which encodes a new low-molecularweight penicillin-binding protein in Bacillus subtilis. J. Bacteriol. 180, 4967-4973.

(47) Warth, A. D., and Strominger, J. L. (1969) Structure of the peptidoglycan of bacterial spores: Occurrences of the lactam of muramic acid. Proc. Natl. Acad. Sci. U.S.A. 64, 528-535.

(48) Mattei, P.-J., Neves, D., and Dessen, A. (2010) Bridging cell wall biosynthesis and bacterial morphogenesis. Curr. Opin. Struct. Biol. 20, 749-755.

(49) Typas, A., Banzhaf, M., van den Berg van Saparoea, B., Verheul, J., Biboy, J., Nichols, R. J., Zietek, M., Beilharz, K., Kannenberg, K., von Rechenberg, M., Breukink, E., den Blaauwen, T., Gross, C. A., and Vollmer, W. (2010) Regulation of peptidoglycan synthesis by outermembrane proteins. Cell 143, 1097-1109.

(50) Peddi, S., Nicholas, R. A., and Gutheil, W. G. (2009) Neisseria gonorrhoeae penicillin-binding protein 3 demonstrates a pronounced preference for $\mathrm{N} \varepsilon$-acylated substrates. Biochemistry 48, 5731-5737.

(51) Kishida, H., Unzai, S., Roper, D. I., Lloyd, A., Park, S.-Y., and Tame, J. R. H. (2006) Crystal structure of penicillin-binding protein 4 (Dac B) from Escherichia coli, both in the native form and covalently linked to various antibiotics. Biochemistry 45, 783-792.

(52) Kumar, I., Josephine, H. R., and Pratt, R. F. (2007) Reactions of peptidoglycan-mimetic $\beta$-lactams with penicillin-binding proteins in vivo and in membranes. ACS Chem. Biol. 2, 620-624.

(53) Nicola, G., Peddi, S., Stefanova, M., Nicholas, R. A., Gutheil, W. G., and Davies, C. (2005) Crystal structure of Escherichia coli penicillin-binding protein 5 bound to a tripeptide boronic acid inhibitor: A role for Ser 110 in deacylation. Biochemistry 44, 82078217.

(54) Nelson, D. R., Ghosh, A. S., Paulson, A. L., and Young, K. D. (2002) Contribution of membrane-binding and enzymatic domains of penicillin-binding proteins to maintenance of uniform cellular morphology in Escherichia coli. J. Bacteriol. 184, 3630-3639.

(55) Potluri, L., Karczmarek, A., Verheul, J., Piette, A., Wilkin, J.-M., Werth, N., Banzhaf, N., Vollmer, W., Young, K. D., Nguyen-Distèche, M., and den Blaauwen, T. (2011) Septal and lateral wall localization of PBP5, the major DD-carboxypeptidase of Escherichia coli, requires substrate recognition and membrane attachment. Mol. Microbiol. 77, 300-323.

(56) Pearson, W. R. (1996) Effective protein sequence comparison. Methods Enzymol. 266, 227-258.

(57) Romeis, T., and Holtje, J.-V. (1994) Penicillin-binding protein $7 / 8$ of Escherichia coli is a DD-endopeptidase. Eur. J. Biochem. 224, 597-604. 
(58) Amanuma, H., and Strominger, J. L. (1980) Purification and properties of penicillin-binding proteins 5 and 6 from Escherichia coli membranes. J. Biol. Chem. 255, 11173-11180.

(59) Van der Linden, M. P. G., de Haan, L., Hoger, M. A., and Keck, W. (1992) Possible role of Escherichia coli PBP6 in stabilization of stationary phase peptidoglycan. J. Bacteriol. 174, 7572-7578.

(60) Chowdhury, C., Nayak, T. R., Young, K. D., and Ghosh, A. S. (2010) A weak DD-carboxypeptidase activity explains the inability of PBP6 to substitute for PBP5 in maintaining normal cell shape in Escherichia coli. FEMS Microbiol. Lett. 303, 76-83.

(61) Chowdhury, C., and Ghosh, A. (2011) Differences in active site microarchitecture explain the dissimilar behaviors of PBP5 and PBP6 in Escherichia coli. J. Mol. Graphics Modell. 29, 650-656.

(62) Chen, Y., Zhang, W., Shi, Q., Hesek, D., Lee, M., Mobashery, S., and Shoichet, B. K. (2009) Crystal structures of penicillin-binding protein 6 from Escherichia coli. J. Am. Chem. Soc. 131, 14345-14354.

(63) Hesek, D., Suvorov, M., Morio, K., Lee, M., Brown, S., Vakulenko, S. B., and Mobashery, S. (2004) Synthetic peptidoglycan substrates for penicillin-binding protein 5 of Gram-negative bacteria. J. Org. Chem. 69, 778-784.

(64) Alaedini, A., and Day, R. A. (1999) Identification of two penicillin-binding multienzyme complexes in Haemophilus influenzae. Biochem. Biophys. Res. Commun. 264, 191-195.

(65) Lee, B. (1971) Conformation of penicillin as a transition-state analog of the substrate of peptidoglycan transpeptidase. J. Mol. Biol. 61, 463-469.

(66) Pratt, R. F. (2008) Substrate specificity of bacterial DDpeptidases (penicillin-binding proteins). Cell. Mol. Life Sci. 65, 21382155 .

(67) Terrak, M., Ghosh, T. K., van Heijenoort, J., Van Beeumen, J., Lampilis, M., Aszodi, J., Ayala, J. A., Ghuysen, J.-M., and NguyenDistèche, M. (1999) The catalytic glycosyl transferase and acyl transferase modules of the cell wall peptidoglycan-polymerizing penicillin-binding protein $1 \mathrm{~b}$ of Escherichia coli. Mol. Microbiol. 34, 350-364.

(68) Lupoli, T. J., Tsukamoto, H., Doud, E. H., Wang, T.-S. A., Walker, S., and Kahne, D. (2011) Transpeptidase-mediated incorporation of D-amino acids into bacterial peptidoglycan. J. Am. Chem. Soc. 133, 10748-10751.

(69) Macheboeuf, P., Di Giulmi, A. M., Job, V., Vernet, T., Dideberg, O., and Dessen, A. (2005) Active site restructuring regulates ligand recognition in class A penicillin-binding proteins. Proc. Natl. Acad. Sci. U.S.A. 102, 577-582.

(70) Lovering, A. L., DeCastro, L., Lim, D., and Strynadka, N. C. J. (2006) Structural analysis of an "open" form of PBP $1 \mathrm{~b}$ from Streptococcus pneumoniae. Protein Sci. 15, 1701-1709.

(71) Lim, D., and Strynadka, N. C. J. (2002) Structural basis for the $\beta$-lactam resistance of PBP 2a from methicillin-resistant Staphylococcus aureus. Nat. Struct. Biol. 9, 870-876.

(72) Fuda, C., Savarov, M., Vakulenko, S. B., and Mobashery, S. (2004) The basis for resistance to $\beta$-lactam antibiotics by penicillinbinding protein 2a of methicillin-resistant Staphylococcus aureus. J. Biol. Chem. 279, 40802-40806.

(73) Fuda, C., Hesek, D., Lee, M., Morio, K., Thomas, N., and Mobashery, S. (2005) Activation for catalysis of penicillin-binding protein 2a from methicillin-resistant Staphylococcus aureus by bacterial cell wall. J. Am. Chem. Soc. 127, 2056-2057.

(74) Chittock, R. S., Ward, S., Wilkinson, A.-S., Caspers, P., Mensch, B., Page, M. G. P., and Wharton, C. W. (1999) Hydrogen-bonding and protein perturbation in $\beta$-lactam acyl-enzymes of Streptococcus pneumoniae penicillin-binding protein PBP2x. Biochem. J. 338, 153159.

(75) Zhao, G.-H., Duez, C., LePage, S., Forceille, C., Rhazi, N., Klein, D., Ghuysen, J.-M., and Frère, J.-M. (1997) Site-directed mutagenesis of the Actinomadura R39 DD-peptidase. Biochem. J. 327, 377-381. 